\title{
Why compromise with an elderly patient?
}

\author{
Ari A. Mennander, MD, PhD
}

From the Tampere University Heart Hospital, Tampere, Finland.

Disclosures: Author has nothing to disclose with regard to commercial support.

Received for publication Sept 26, 2016; accepted for publication Sept 26, 2016; available ahead of print Nov 17, 2016.

Address for reprints: Ari A. Mennander, MD, PhD, Tampere University Heart Hospital, SDSKIR, Teiskontie 35, PL 2000 Tampere, Finland (E-mail: ari.mennander@sydansairaala.fi).

J Thorac Cardiovasc Surg 2017;153:536

$0022-5223 / \$ 36.00$

Copyright $(2016$ by The American Association for Thoracic Surgery

http://dx.doi.org/10.1016/j.jtcvs.2016.09.076

Hata and colleagues ${ }^{1}$ share their outstanding experience with a fast-track-like solution for surgery using a J-shaped open stent graft. The mean patient age was 81.6 years, with patients ranging in age from 80 to 90 years. From sternotomy, circulatory arrest at $28^{\circ} \mathrm{C}$ without cerebral perfusion, but aortic crossclamping, was utilized and an open stent graft was inserted without balloon dilation in the descending thoracic aorta. The aortic incision was placed between the left common carotid and left subclavian arteries. This restricted technique was offered to exclude distal aortic arch aneurysm (DAAA), and all 24 patients recovered completely from surgery.

The natural risk of rupture of DAAA and descending aortic aneurysm exceeding $6 \mathrm{~cm}$ in diameter is considerable: Approximately $20 \%$ of aneurysms have been estimated to rupture in as short as 36 months. ${ }^{2}$ Most DAAA may be dealt with using an endovascular solution such as thoracic endovascular aortic repair. ${ }^{3}$ Life expectancy among Japanese octogenarians is relatively high, 7.86 years in men and 10.63 years in women. ${ }^{4}$ It is conceivable that the Japanese octogenarian patients studied by Hata and colleagues ${ }^{1}$ underwent surgery because the risk of postoperative stroke due to mural thrombi within the aorta could be a major concern during thoracic endovascular aortic repair. ${ }^{5}$ The mental questionnaire the authors employed is commendable; not only the absence of cerebral strokes determines the outcome of surgical success. The authors do a fine job of discussing how rapid rewarming after $28^{\circ} \mathrm{C}$ may have been beneficial for their patients.

Surgeons need to balance the risks associated with prophylactic surgery and those of not operating. Preoperative information, including at least the diameter of the DAAA, is warranted before making the decision for surgery. What would an elderly patient gain from tolerating even a compromised restricted technique if there is no guarantee of completely excluding the possibility of DAAA? Follow-up computed tomography scanning to evaluate plausible remodeling of the aorta after surgery may be considered. After the pilot experience described by Hata and colleagues, ${ }^{1}$ we need thorough, complete, and critical evaluation of the technique.

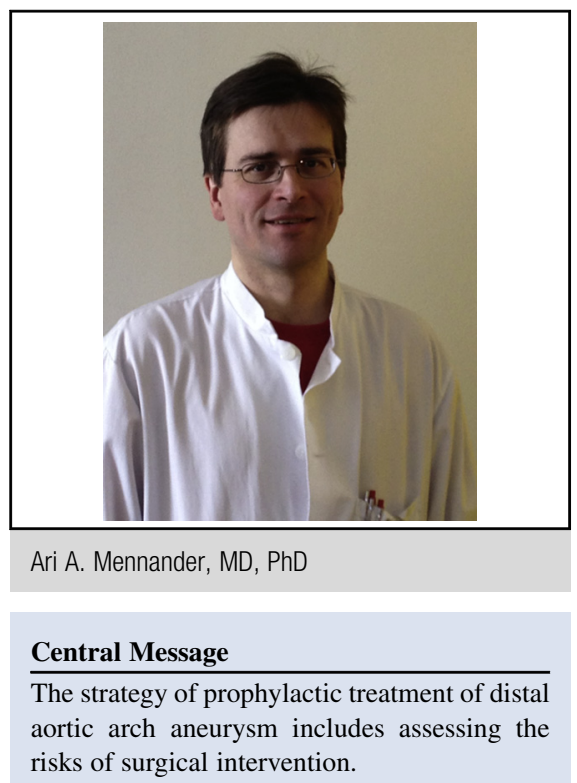

See Article page 530.

Quality of life may be immensely associated with a patient's physical activity of the moment, and worrisome speculation of a future endangered by a possible aneurysm rupture may be less of a matter in elderly persons. The key question remains: Does a physically deconditioned elderly patient desire surgical intervention that could include follow-up and adjunct treatment such as a possible second-stage operation? In an elective case, there is plenty of time to discuss treatment strategy with a patient. It is up to the medical community to listen when an elderly patient is willing to manage his or her condition with prophylactic treatment. Appeasing surgical ambition should not be the aim of any treatment, and a limited surgical option, such as that presented by Hata and colleagues, ${ }^{1}$ may be the right individual solution for some patients — regardless of age — or it may not.

\section{References}

1. Hata M, Orime Y, Wakui S, Nakamura T, Hinoura R, Harada A, et al. Efficacy of a newly modified technique for distal limited open stenting in octogenarians with aortic arch aneurysm. J Thorac Cardiovasc Surg. 2017;153:530-5.

2. Yiu RS, Cheng SW. Natural history and risk factors for rupture of thoracic aortic arch aneurysms. J Vasc Surg. 2016;63:1189-94.

3. Rylski B, Blanke P, Siepe M, Kari FA, Euringer W, Sudkamp M, et al. Results of high-risk endovascular procedures in patients with non-dissected thoracic aortic pathology: intermediate outcomes. Eur J Cardiothorac Surg. 2013;44:156-62.

4. Kawachi Y, Nakashima A, Kosuga T, Tomoeda H, Nishimura Y. Early and late results of cardiac and thoracic aortic surgery in octogenarians: comparison with high-risk younger patients. Circ J. 2003;67:539-44.

5. Patel HJ, Shillingford MS, Williams DM, Upchurch GR Jr, Dasika NL, Prager RL, et al. Survival benefit of endovascular descending thoracic aortic repair for the high-risk patient. Ann Thorac Surg. 2007;83:1628-33. 